\title{
A sulfated polysaccharide, fucoidan, enhances the immunomodulatory effects of lactic acid bacteria
}

\author{
TADAOMI KAWASHIMA ${ }^{1}$, KATSURA MURAKAMI ${ }^{2}$, IKUKO NISHIMURA ${ }^{1}$, \\ TAKAHISA NAKANO $^{2}$ and AKIO OBATA ${ }^{1}$ \\ ${ }^{1}$ Research and Development Division, Kikkoman Corporation, Noda City, Chiba 278-0037; \\ ${ }^{2}$ Health Care Department, Riken Vitamin Corporation, Chiyoda-ku, Tokyo 102-0083, Japan
}

Received October 12, 2011; Accepted November 8, 2011

DOI: $10.3892 / \mathrm{ijmm} .2011 .854$

\begin{abstract}
Fucoidan, a sulfated polysaccharide contained in brown algae, has a variety of immunomodulatory effects, including antitumor and antiviral effects. On the other hand, lactic acid bacteria (LAB) also have immunomodulatory effects such as anti-allergic effects. In this study, we demonstrated that fucoidan enhances the probiotic effects of LAB on immune functions. By using Peyer's patch cells and spleen cells in vitro, fucoidan amplified interferon (IFN)- $\gamma$ production in response to a strain of LAB, Tetragenococcus halophilus KK221, and this activity was abolished by desulfation of fucoidan. Moreover, this IFN- $\gamma$ response was abolished by interleukin (IL)-12 neutralization. These results indicate that fucoidan enhanced IL-12 production in response to KK221, resulting in promoting IFN- $\gamma$ production. In an in vivo study, Th1/Th2 immunobalance was most improved by oral administration of both fucoidan and KK221 to ovalbumin-immunized mice. These findings suggest that fucoidan can enhance a variety of beneficial effects of $\mathrm{LAB}$ on immune functions.
\end{abstract}

\section{Introduction}

Brown algae seaweeds contain fucoidan, a complex sulfated polysaccharide, and it has a variety of biological activities, including anti-inflammatory, antiviral, and antitumor effects (1-5). In an in vitro analysis, fucoidan was reported to enhance phagocytic activity of macrophages and $\mathrm{B}$ cell blastogenesis, but did not change the release of $\mathrm{NO}_{2}$ by macrophages (2). These effects led to the augmentation of natural killer (NK) cell activity and $\mathrm{T}$ cell cytotoxicity, resulting in an antiviral action (2). In another report, oral administration of fucoidan to

Correspondence to: Mr. Tadaomi Kawashima, Research and Development Division, Kikkoman Corporation, 399 Noda, Noda City, Chiba 278-0037, Japan

E-mail: takawashima@mail.kikkoman.co.jp

Key words: immunomodulation, probiotics, lactic acid bacteria, fucoidan
T cell receptor transgenic (DO11.10-Tg) mice promoted antitumor activities by enhancing T helper type 1 (Th1) immune responses and resultant $\mathrm{T}$ cell-mediated NK cell activation (6). It has also been shown that treatment of dendritic cells (DCs) with fucoidan enhances interferon (IFN)- $\gamma$ production by $\mathrm{CD}^{+} \mathrm{T}$ cells and induces $\mathrm{T}$ cell cytotoxicity against antigenexpressing human cancer cells (7). These reports suggest that fucoidan enhances the antigen-presenting activity of DCs and macrophages, thereby inducing upregulation of $\mathrm{CD} 8^{+} \mathrm{T}$ cell cytotoxicity or NK cell activity, resulting in activation of antiinfectious and antitumor responses.

Recently, many reports have revealed that orally administered lactic acid bacteria (LAB) are protective against immune (8-13) and infectious (14-19) diseases. Th cells are key components of acquired immune responses, and are classified into several subsets such as Th1, Th2, Th17, and regulatory $\mathrm{T}$ cells (20). Because Th 2 cell development preferentially initiates allergic responses, foods that support Th1 development are considered a useful dietary supplement when taken as a precaution against allergy development (21). Some LAB influence the production of a variety of cytokines from DCs and macrophages $(22,23)$, notably interleukin-12 (IL-12), which induces Th1 cell development.

Certain strains of LAB have been demonstrated to induce IL-12 production from DCs and macrophages, converting a Th2 response into a Th1-dominated response, resulting in suppression of antigen-specific immunoglobulin $\mathrm{E}$ (IgE) production in mice (8-10). We have previously reported anti-allergic effects of Tetragenococcus halophilus KK221 (also called strain Th221 in our previous reports), which was isolated from soy sauce brewing $(10,13)$. This strain induces a profound production of IL-12 from macrophages, and oral administration of KK221 has been shown to suppress allergic symptoms in mice and humans $(10,13)$. As demonstrated in these reports, some strains of LAB activate DCs and macrophages to produce a variety of cytokines, and influence the differentiation of naïve $\mathrm{T}$ cells into Th1 cells, leading to anti-allergic effects.

As described above, although fucoidan and LAB target different cells and signaling pathways, both have multiple effects on immune function. In this study, we evaluated the synergistic effects of fucoidan and KK221, focusing on cytokine production in vitro and $\mathrm{Th} 1 / \mathrm{Th} 2$ immunobalance in vivo. 


\section{Materials and methods}

Bacteria. Tetragenococcus halophilus KK221 was grown by stationary culture in MRS medium (BD Diagnostics, Franklin Lakes, $\mathrm{NJ})$ containing $10 \%(\mathrm{w} / \mathrm{v}) \mathrm{NaCl}$ at $30^{\circ} \mathrm{C}$ for $24-48 \mathrm{~h}$. After completion of the culture, bacteria were heat-killed at $95^{\circ} \mathrm{C}$ for $10 \mathrm{~min}$, washed twice with saline, and used for in vitro and in vivo assessment. To label KK221 with fluorescein isothiocyanate (FITC), heat-killed KK221 was incubated with $100 \mu \mathrm{g} / \mathrm{ml}$ FITC isomer-I (Dojindo Laboratories, Kumamoto, Japan). Thereafter, KK221 was washed 3 times with saline, and used for phagocytosis assessment.

Fucoidan. Fucoidan was isolated from the dried sporophyll of Undaria piaantifida as previously described (24). Desulfated fucoidan was prepared from fucoidan following a protocol published previously (25). Low molecular-weight fucoidan (LM-fucoidan) was prepared by treatment with acid, as follows: hydrolysis of fucoidan $(10 \mathrm{~g})$ was achieved by dissolution in $1000 \mathrm{ml}$ of $2 \mathrm{mM} \mathrm{HCl}$ at high temperature using an autoclave apparatus $\left(120^{\circ} \mathrm{C}, 3 \mathrm{~h}\right)$. This solution was neutralized by $1 \mathrm{M}$ $\mathrm{NaOH}$. The neutralized fucoidan was fractionated using ultrafiltration with 50 and $3 \mathrm{kDa}$ molecular weight cut-off membranes. LM-fucoidan, in the fraction between 50 and $3 \mathrm{kDa}$, was obtained and freeze-dried. Positive identification of LM-fucoidan in this fraction was achieved by gel filtration using (in series) Toyopearl HW-65F (8 mm x 1,000 mm) and Toyopearl HW-40F ( $8 \mathrm{~mm} \times 1,000 \mathrm{~mm}$ ) columns purchased from Toyosoda (Tokyo, Japan). The sample $(20 \mu \mathrm{l})$ was injected, eluted with $0.05 \%$ formic acid solution at a flow rate of $1 \mathrm{ml} / \mathrm{min}$ at room temperature, and detected with a differential refractometer.

Reagents. Fucose, a carbohydrate component of fucoidan, was purchased from Wako (Osaka, Japan). Anti-IL-12 monoclonal antibody (mAb) and control Ab (rat IgG2a) were purchased from eBioscience (San Diego, CA). Ovalbumin (OVA, Grade V) was purchased from Sigma (St. Louis, MO).

Animals. For in vitro and in vivo experiments, male BALB/c mice were purchased from Charles River Co. (Atsugi, Japan). These experiments were approved and supervised by the local Ethics Committee according to the Guidelines of the Japanese Association for Laboratory Animal Science (published in 1987) and the Guidelines for Animal Experiments of the Research and Development Division, Kikkoman Corporation.

Cell preparation. Mouse peritoneal macrophages were prepared from male BALB/c mice (6-10-weeks-old) after stimulation by an intraperitoneal injection of fluid thioglycolate medium ( $2 \mathrm{ml}$, BD Diagnostics). Cell suspensions containing DCs were prepared from spleens, mesenteric lymph nodes, and Peyer's patches of male BALB/c mice (6-10-weeks-old) by digestion of each organ with type I collagenase.

In vitro cytokine production assay. Murine macrophages $\left(2 \times 10^{5}\right)$ were stimulated with heat-killed KK221 $\left(2 \times 10^{5}\right)$ for 24 h. Cells $\left(5 \times 10^{5}\right)$ from spleens, mesenteric lymph nodes, or Peyer's patches were cultured with $5 \times 10^{5}$ KK 221 in RPMI-1640 (Gibco, Eggenstein, Germany) containing 10\% fetal bovine serum (FBS, Nichirei, Tokyo, Japan) for $48 \mathrm{~h}$ at $37^{\circ} \mathrm{C}$. Culture supernatants were collected, and cytokine levels were measured by enzyme-linked immunosorbent assay (ELISA).

Assay for phagocytosis of bacteria. Murine macrophages $\left(2 \times 10^{5}\right)$ were pre-treated in the presence or absence of fucoidan for $2 \mathrm{~h}$ at $37^{\circ} \mathrm{C}$. Thereafter, fucoidan-treated or untreated macrophages were incubated with FITC-labeled, heat-killed $\mathrm{KK} 221\left(2 \times 10^{5}\right)$ for $4 \mathrm{~h}$ at $37^{\circ} \mathrm{C}$. After incubation, macrophages were collected using trypsin (Sigma, St. Louis, MO), and the ratio of $\mathrm{FITC}^{+}$cells was analyzed by flow cytometry.

In vivo experiments. For the OVA-immunization test, 6-week-old male BALB/c mice ( $\mathrm{n}=6$ per group) were injected intraperitoneally on Days 0 and 14 with $20 \mu \mathrm{g}$ of OVA and $2 \mathrm{mg}$ of $\mathrm{Al}(\mathrm{OH})_{3}(\mathrm{Sigma})$ as adjuvant in a total volume of $0.2 \mathrm{ml}$. The mice received daily oral administration of saline, fucoidan ( $5 \mathrm{mg} /$ day), KK221 (4x10\%/day), and fucoidan/KK221 $\left(1 \mathrm{mg} /\right.$ day and $4 \times 10^{8} /$ day, respectively) on days $0-20$. Sera were collected on Day 21, and OVA-specific IgE levels were measured by ELISA. Sera were also collected from 3 naïve mice as OVA-untreated control. On Day 21 , spleen cells $\left(1 \times 10^{7}\right.$ cells/well) were incubated in culture medium (RPMI-1640 containing $10 \%$ FBS) with $100 \mu \mathrm{g} / \mathrm{ml}$ OVA in a 24-well flatbottom plate at $37^{\circ} \mathrm{C}$ for $72 \mathrm{~h}$. IFN- $\gamma$ and IL-4 concentrations in each supernatant were quantified by ELISA.

ELISA. IL-12p70, IFN- $\gamma$, IL-4, IL-6 and TNF- $\alpha$ concentrations in culture medium were determined using Mouse OptEIA ${ }^{\mathrm{TM}}$ ELISA Sets (BD Biosciences, San Jose, CA), following the manufacturer's instructions. OVA-specific IgE levels were determined by ELISA as previously described (26).

Statistical analysis. Data are presented as the mean \pm SD. In in vitro tests, statistical analyses were carried out using the Student's t-test, and probability $\mathrm{P}<0.05$ were considered to be significant. In the in vivo analysis, statistical comparisons were made by one-way analysis of variance (ANOVA), followed by a Duncan multiple-comparison test. Differences were considered to be significant when $\mathrm{P}<0.05$.

\section{Results}

Cytokine responses of macrophages to fucoidan and $L A B$ strain, KK221. We have previously reported that KK221 induces a high level of IL-12 production by macrophages (10). We therefore evaluated the effect of fucoidan on IL-12 induction by KK221. Peritoneal macrophages stimulated with fucoidan produced considerably less IL-12 than those stimulated with KK221, while co-stimulation with fucoidan and KK221 enhanced IL-12 production in a fucoidan dosedependent manner (Fig. 1A). Although IL-6 and TNF- $\alpha$ were secreted by peritoneal macrophages in response to both fucoidan and KK221 individually, this IL6/TNF- $\alpha$ response was potentiated by co-stimulation with fucoidan and KK221 (Fig. 1B and C). Fucose, a carbohydrate component of fucoidan, did not affect cytokine production in response to KK221 (Fig. 1A-C). These results indicate that fucoidan and KK221 synergistically enhance the cytokine responses 
A

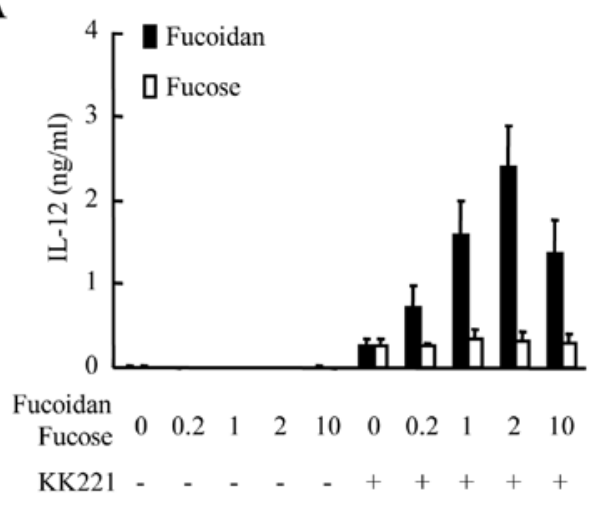

B

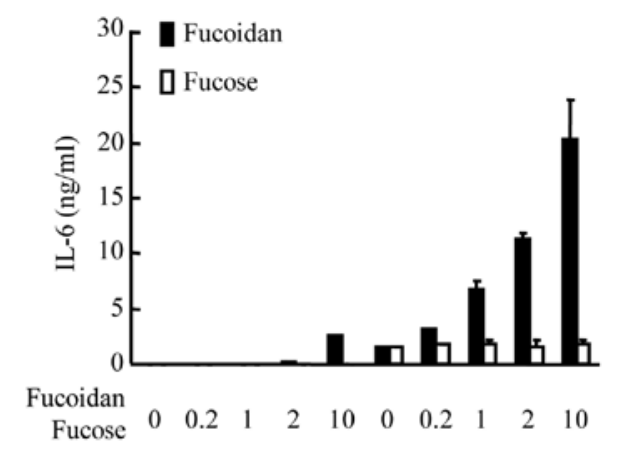

$\mathrm{C}$

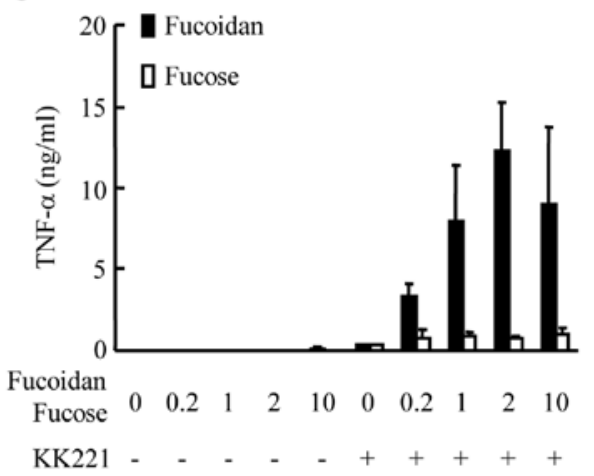

D
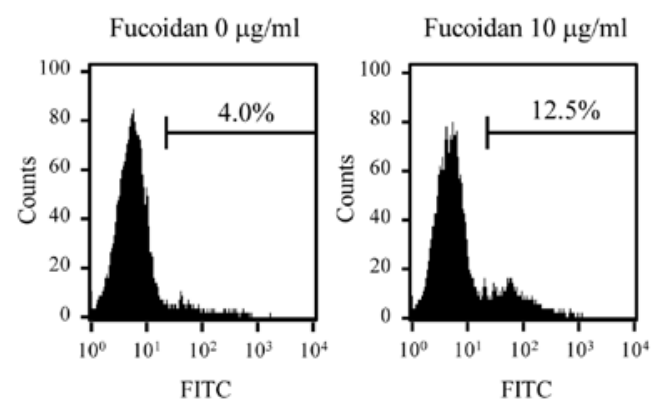

Figure 1. Mouse peritoneal macrophages from BALB/c mice were stimulated with KK221 and/or fucoidan (0-10 $\mu \mathrm{g} / \mathrm{ml})$ for $24 \mathrm{~h}$. (A) IL-12, (B) IL-6 and (C) TNF- $\alpha$ concentrations in the culture supernatants were measured by ELISA. Results are shown as the mean \pm SD of triplicates from a single experiment, representative of 3 independent experiments. (D) Mouse peritoneal macrophages were incubated with FITC-labeled KK221 pre-treated with 0 or $10 \mu \mathrm{g} / \mathrm{ml}$ fucoidan. Values in the figures represent the ratio of $\mathrm{FITC}^{+}$ cells. Data are representative of 3 independent experiments.

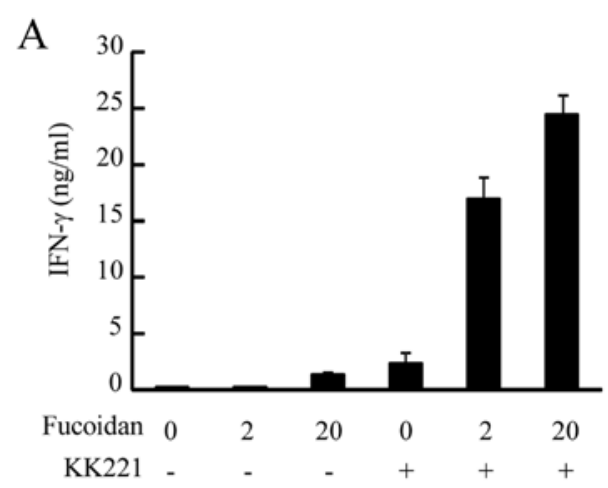

$\mathrm{B}$

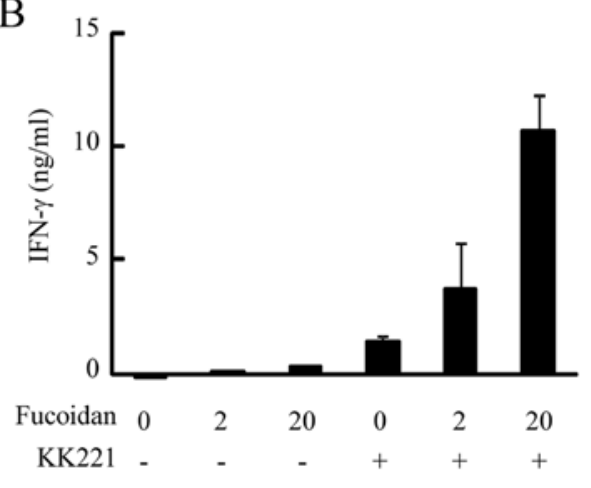

$\mathrm{C}$

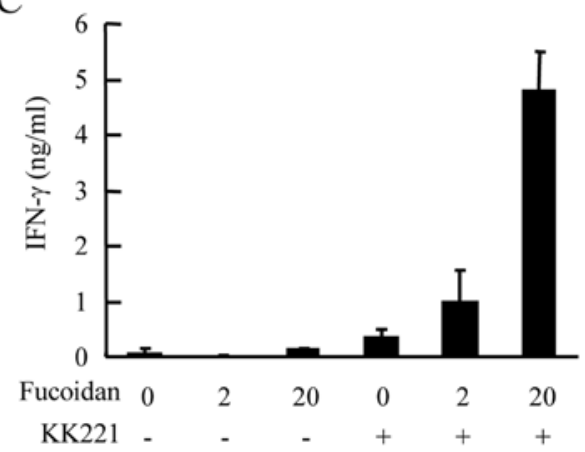

Figure 2. (A) Spleen cells, (B) mesenteric lymph node cells, or (C) Peyer's patch cells from BALB/c mice were cultured with KK221 and/or fucoidan $(0-20 \mu \mathrm{g} / \mathrm{ml})$ at $37^{\circ} \mathrm{C}$ for $48 \mathrm{~h}$. IFN- $\gamma$ concentration in the culture supernatants was measured by ELISA. Results are shown as the mean \pm SD of triplicates within a single experiment, which is representative of 3 independent experiments.

of peritoneal macrophages. To analyze KK221 phagocytosis by macrophages, peritoneal macrophages were incubated with FITC-labeled KK221 in the presence of fucoidan. We found that fucoidan supplementation increased the ratio of $\mathrm{FITC}^{+}$ macrophages (Fig. 1D), indicating that fucoidan upregulates KK221 phagocytosis by macrophages.

Cytokine responses of cells from spleens, mesenteric lymph nodes and Peyer's patches to fucoidan and KK221. To evaluate this synergistic effect on cytokine responses by other cells, cell suspensions containing DCs were prepared from mouse spleens, mesenteric lymph nodes, and Peyer's patches of mice. In cells from each tissue, fucoidan and KK221 stimulation caused the synergistic upregulation of IFN- $\gamma$ production in a fucoidan dose-dependent manner (Fig. 2). Production of 

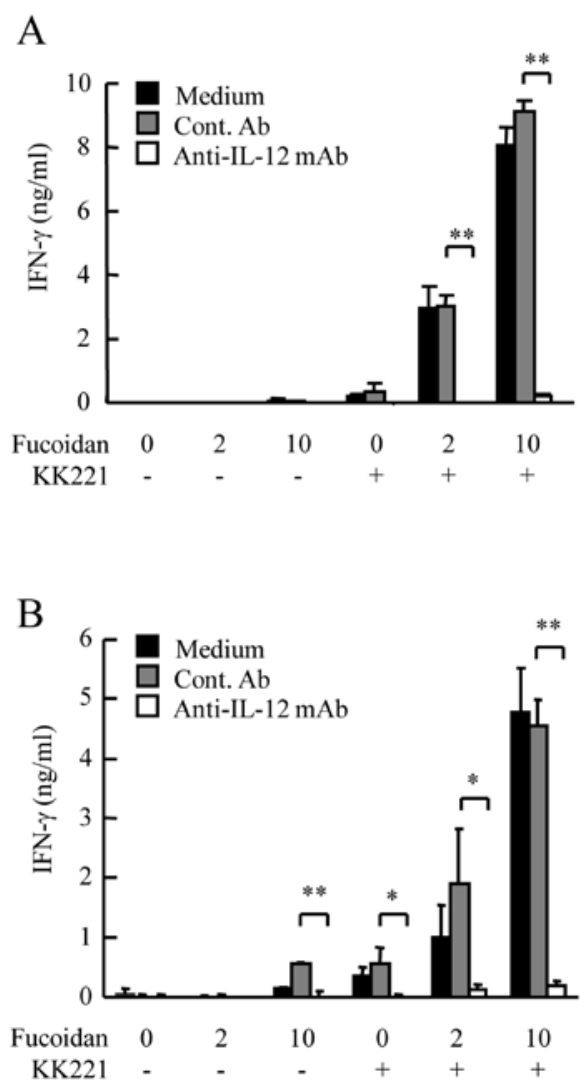

Figure 3. (A) Cells from the spleens or (B) Peyer's patches of BALB/c mice were cultured with KK221 and/or fucoidan $(0-10 \mu \mathrm{g} / \mathrm{ml})$ in the presence of control antibody (Cont. $\mathrm{Ab}$ ) or anti-IL- $12 \mathrm{mAb}$ at $37^{\circ} \mathrm{C}$ for $48 \mathrm{~h}$. IFN- $\gamma$ concentration in the culture supernatants was measured by ELISA. Results are shown as the mean $\pm \mathrm{SD}$. Data are representative of 3 independent experiments $* \mathrm{P}<0.05, * * \mathrm{P}<0.01$, significant differences between the indicated columns. other cytokines such as IL-6 and IL-10 were also enhanced by stimulation with fucoidan and KK221 (data not shown). These results indicate that fucoidan upregulates cytokine responses in tissue DCs as well as peritoneal macrophages, resulting in enhancement of IFN- $\gamma$ production by $\mathrm{T}$ cells and other cells.

IL-12 neutralization assay. IL-12 was upregulated by co-stimulation with KK221 and fucoidan (Fig. 1A). IL-12 is known to promote IFN- $\gamma$ production and to enhance Th1 immune responses (27). To investigate whether the synergistic enhancement of IL-12 production by fucoidan and KK221 causes concomitant upregulation of IFN- $\gamma$, we added antiIL-12 mAb or control Ab to the cell culture medium. IFN- $\gamma$ production from spleen cells in response to either KK221 or fucoidan/KK221 was significantly reduced by anti-IL-12 mAb (Fig. 3A). IFN- $\gamma$ production from Peyer's patch cells stimulated with fucoidan, KK221, or fucoidan/KK221 was also abolished by anti-IL-12 mAb (Fig. 3B). These results indicate that fucoidan and KK221 stimulate IL-12 production from DCs that then drives IFN- $\gamma$ production by T cells.

Desulfation of fucoidan. Fucoidan is a polysaccharide containing sulfate groups. In this experiment, we tried to determine which moiety of fucoidan mediates the enhancement of cytokine responses. Desulfated fucoidan contained only $1.2 \%$ (w/w) sulfate, compared to $26.7 \%(w / w)$ in normal fucoidan (Table I). Using acid-hydrolysis, we prepared LM-fucoidan (MW range: 2-206 kDa; MW of peak polysaccharide: $20 \mathrm{kDa}$ ) from normal fucoidan (MW range: 3-400 kDa; MW of peak polysaccharide: $67 \mathrm{kDa}$ (Fig. 4A). LM-fucoidan contained $12.6 \%(\mathrm{w} / \mathrm{w})$ sulfate (Table I), indicating that the sulfate group content was partially reduced by hydrolytic reduction
A

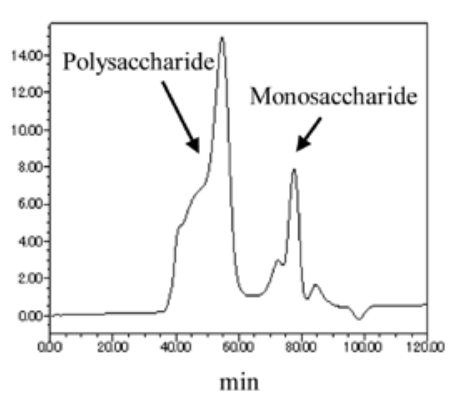

B

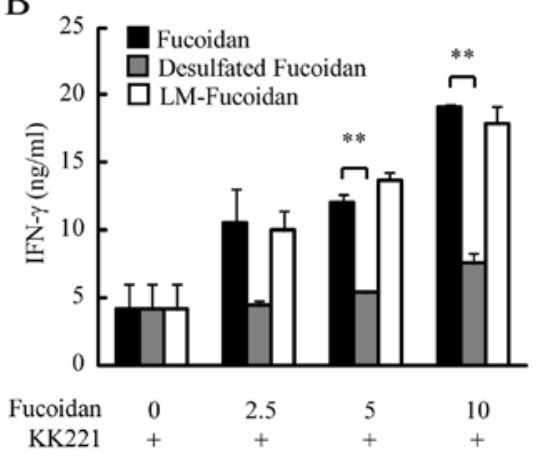

LM-Fucoidan

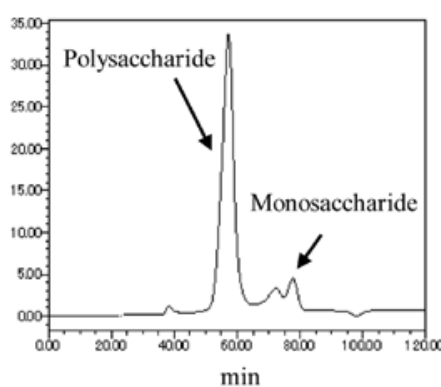

$\mathrm{C}$

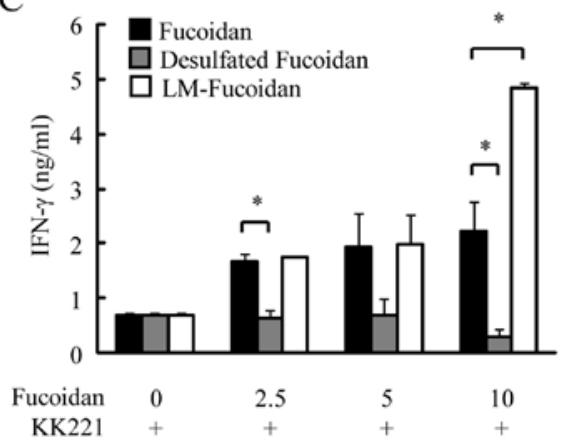

Figure 4. (A) Chromatogram of fucoidan and low molecular-weight fucoidan (LM-fucoidan). (B) Spleen cells, or (C) Peyer's patch cells from BALB/c mice were cultured with KK221 and either fucoidan, desulfated fucoidan or LM-fucoidan $(0-10 \mu \mathrm{g} / \mathrm{ml})$ at $37^{\circ} \mathrm{C}$ for $48 \mathrm{~h}$. IFN- $\gamma$ concentration in the culture supernatants was measured by ELISA. Results are shown as the mean $\pm \mathrm{SD}$. Data are representative of 3 independent experiments. ${ }^{*} \mathrm{P}<0.05$, $* * \mathrm{P}<0.01$. 
Table I. Ratio of sulfur and sulfate group in fucoidan, desulfated fucoidan, and low molecular-weight fucoidan (LM-fucoidan).

\begin{tabular}{lcc}
\hline Sample name & $\begin{array}{c}\text { Sulfur } \\
(\% \text { w/w })\end{array}$ & $\begin{array}{r}\text { Sulfate group } \\
(\% \text { w/w })\end{array}$ \\
\hline Fucoidan & 8.9 & 26.7 \\
Desulfated fucoidan & 0.4 & 1.2 \\
LM-fucoidan & 4.2 & 12.6 \\
\hline
\end{tabular}

of fucoidan molecular weight. In combination with KK221, desulfated fucoidan failed to enhance IFN- $\gamma$ production from cultured spleen and Peyer's patch cells, whereas LM-fucoidan activity was not different to untreated fucoidan (Fig. 4B). These results indicate that the fucoidan sulfate group is essential for upregulating cytokine responses.

Effects of fucoidan and KK221 on Th1/Th2 immunobalance in vivo. To evaluate whether the synergistic effects of fucoidan and KK221 translated to the in vivo situation, antigen-specific responses were tested using OVA-immunized mice. It has been reported that $\operatorname{IgE}$ production is suppressed when fucoidan is intraperitoneally, but not orally, administered prior to the first immunization with OVA (4). Serum OVA-specific IgE was enhanced by intraperitoneal injection of OVA/Alum indicating that systemic immune responses to the antigen were induced. Oral administration of fucoidan alone had no effect on the serum OVA-specific IgE level, whereas this was significantly suppressed in mice fed either KK221 or fucoidan/KK221 (Fig. 5A). We have previously described this suppression of OVA-specific IgE production by oral administration of KK221 (10). To evaluate Th1/Th2 immunobalance, IFN- $\gamma$ (secreted by Th1 cells) and IL-4 (secreted by Th 2 cells) were quantified by stimulating spleen cells from each mouse with OVA. IFN- $\gamma$ production was significantly upregulated only in the fucoidan/ KK221-treated group, whereas IL-4 production was significantly suppressed in this group (Fig. 5B). Together, these results demonstrate that, both in vitro and in vivo, co-administration of fucoidan and KK221 dramatically enhances Th1 immune responses and suppresses allergic responses (Figs. 1 and 2).

\section{Discussion}

In this study, we demonstrated that fucoidan enhanced the antiallergic effect of a probiotic strain of LAB, Tetragenococcus halophilus KK221, by stimulating cytokine production from antigen-presenting cells (APCs), and that fucoidan needs sulfate groups, but not the full length of its polysaccharide, to exert this activity. In our in vivo study, fucoidan enhanced the effect of KK221 administration on improvement of Th1/Th2 immunobalance. Moreover, one of the mechanisms contributing to these effects was the promotion of KK221 phagocytosis by macrophages and/or dendritic cells. Enhancement of macrophage phagocytic activity by fucoidan or other sulfated polysaccharides has been demonstrated in several reports $(2,28,29)$, and could be involved in the synergistic activation of in vitro cytokine production and in vivo anti-allergic immune responses that we observed in response to fucoidan and KK221.
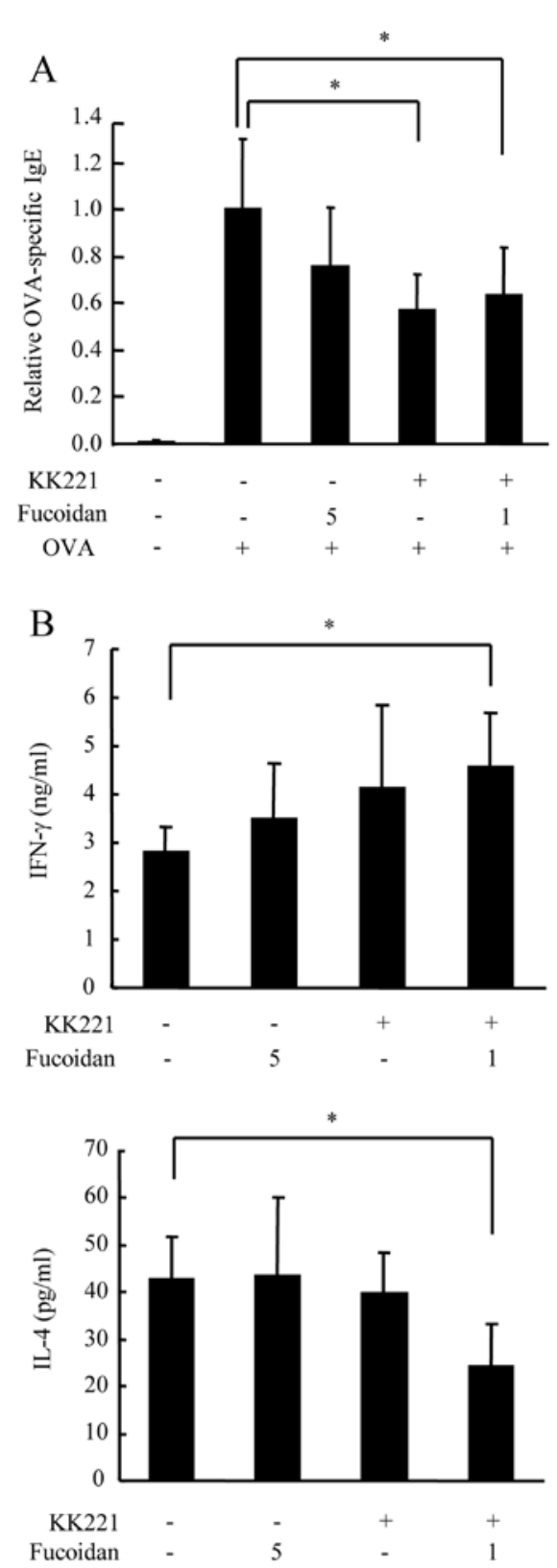

Figure 5. Suppression of serum OVA-specific IgE levels and improvement of Th1/Th2 immunobalance by oral administration of fucoidan and KK221. Saline, fucoidan (5 mg/day), KK221 (4x10 $/$ day), fucoidan + KK221 (1 mg/day and $4 \times 10^{8} /$ day, respectively) were orally administered during the test period. OVA/Alum was injected intraperitoneally on Days 0 and 14. Serum was collected from each mouse and from 3 non-immunized mice on Day 21. (A) OVA-specific IgE in serum was quantified by ELISA. Results are shown as values relative to the OVA-immunized control group. Data are shown as the mean \pm SD. "Significant differences between the indicated columns. (B) Spleens were collected from OVA-immunized mice on Day 21. Spleen cells were cultured in the presence of OVA $(100 \mu \mathrm{g} / \mathrm{ml})$ for 3 days. IFN- $\gamma$ and IL- 4 concentrations in culture supernatants were quantified by ELISA. Data are shown as the mean \pm SD. *Significant difference between the indicated columns.

Several reports have demonstrated that the sulfate content of fucoidan is important for its anticancer (30) and antiviral (31) activities. Sulfated fucans were responsible for the antiviral activity of certain fractions isolated from a water extract of brown seaweed (31). In our study, we show that degradation of the sulfate groups abolishes the synergistic enhancement of cytokine production in response to KK221. This role of 
sulfate groups has precedents in other polysaccharides. A polysaccharide of Grifola frondosa mycelia enhances antitumor effects and peritoneal macrophage phagocytosis by chemical sulfation (28), and a sulfated derivative of $\beta$-glucan isolated from sporophytes of Laminaria digitata stimulates phagocytic and NK cell activity (29). In the case of other types of $\beta$-glucan, we confirmed that those from Lentinula edodes and Saccharomyces cerevisiae (Wako, Osaka, Japan) failed to enhance cytokine production by peritoneal macrophages in response to LAB (data not shown). These data indicate that polysaccharide sulfate groups are responsible for some of their immunological functions. Although decreasing the MW of fucoidan by hydrolysis did not change its effects on cytokine production in our experiment, a recent report has shown that antitumor activity of fucoidan is significantly enhanced by lowering its MW (32). However, this only occurred following depolymerization in mild conditions (boiling for $5 \mathrm{~min}$ ), whereas our hydrolysis conditions $\left(120^{\circ} \mathrm{C}\right.$ for $\left.3 \mathrm{~h}\right)$ were much harsher, resulting in desulfation. Therefore, if we were to reduce the MW of fucoidan without causing desulfation, we might expect that its bioactivities (e.g. antiviral or antitumor activity) would be similarly enhanced.

Activation of innate immunity is a critical step in the development of acquired immunity (33), and is mediated by Toll-like receptors (TLRs) (34). Various bacterial components are recognized by TLRs which, when engaged, induce APCs to secrete various cytokines and chemokines. The TLR family is composed of at least 11 members, with each member recognizing different molecular structures or classes of microorganisms. TLR2 and TLR4 recognize cell wall components of gram-positive bacteria such as lipoteichoic acid and peptidoglycan, and TLR9 recognizes bacterial CpG-DNA (34). TLR 2 and TLR4 are expressed at the cell surface, while TLR9 is expressed in endosomes (34). Recently, the specific TLRs involved in $\mathrm{LAB}$ recognition and cytokine production by $\mathrm{DCs}$ and macrophages have been identified (35-38). Rigaux et al have reported that IL-12p40 secretion by mouse DCs in response to L. plantarum NCIMB8826 was dependent on TLR2- and TLR9-mediated signaling (37). A second report showed that a $\mathrm{CpG}$ oligonucleotide from some LAB activates the TLR9 signaling pathway (38). Endosomal TLR9 recognition of bacterial oligonucleotide may occur after phagocytosis and digestion of bacteria. We revealed here that fucoidan enhances KK221 phagocytosis by macrophages, which is likely to activate the TLR signaling pathway via endosomal TLRs, especially TLR9, leading to enhanced IL-12 production and Th1 cell activation. This mechanism neatly explains the synergistic effect of fucoidan and KK221 in improving Th1/Th2 immunobalance.

It has been shown that oral administration of LAB induces $\mathrm{CD} 4{ }^{+} \mathrm{CD} 25^{+} \mathrm{Foxp}^{+}$regulatory $\mathrm{T}$ cells, which suppress allergic disorders such as asthma or food allergy $(39,40)$. In Peyer's patches and spleen, these cells cause suppression of $\operatorname{IgE}$ production (41). Although we have focused here on activation of Th1 immune responses by oral administration of KK221 and fucoidan, induction of regulatory $\mathrm{T}$ cell differentiation could also lead to improvement of allergic symptoms. Besides being anti-allergic, KK221 also has an anti-inflammatory effect against dextran sulfate sodium-induced experimental colitis (unpublished observation), and other probiotic strains have anti-infectious effects against pathogenic bacteria, such as Listeria monocytogenes or Escherichia coli $(14,15)$, and viruses (16-19). These observations indicate that oral administration of probiotic LAB contributes to the maintenance of immune homeostasis and augments the systemic immune system through gut-associated lymphoid tissues (GALT), a major site of host encounter with exogenous antigens and pathogens. Because fucoidan enhances KK221-induced APC cytokine responses in vitro, fucoidan might also be expected to augment these various other probiotic effects. We are currently investigating whether these synergistic effects of LAB and fucoidan are induced in mouse models of autoimmune diseases, inflammatory bowel diseases, and infection by pathogenic bacteria or viruses. We also aim to identify which subset of DCs or macrophages responds to fucoidan and contributes to these effects in lamina propria or Peyer's patches in the small intestine.

\section{Acknowledgements}

We thank Mr. K. Matsushima for scientific discussion. We also thank Mr. M. Adachi and Mrs. K. Nagamura for technical assistance.

\section{References}

1. MatsumotoS,Nagaoka M,Hara T,Kimura-Takagi I,Mistuyama K and Ueyama S: Fucoidan derived from Cladosiphon okamuranus Tokida ameliorates murine chronic colitis through the downregulation of interleukin-6 production on colonic epithelial cells Clin Exp Immunol 136: 432-439, 2004.

2. Hayashi K, Nakano T, Hashimoto M, Kanekiyo K and Hayashi T: Defensive effects of a fucoidan from brown alga Undaria pinnatifida against herpes simplex virus infection. Int Immunopharmacol 8: 109-116, 2008.

3. Hidari KI, Takahashi N, Arihara M, Nagaoka M, Morita K and Suzuki T: Structure and anti-dengue virus activity of sulfated polysaccharide from a marine alga. Biochem Biophys Res Commun 376: 91-95, 2008.

4. Maruyama H, Tamauchi $\mathrm{H}$, Hashimoto $\mathrm{M}$ and Nakano T: Suppression of Th2 immune responses by mekabu fucoidan from Undaria pinnatifida sporophylls. Int Arch Allergy Immunol 137: 289-294, 2005.

5. Maruyama H, Tamauchi H, Hashimoto $M$ and Nakano T: Antitumor activity and immune response of Mekabu fucoidan extracted from sporophyll of Undaria pinnatifida. In Vivo 17: 245-249, 2003.

6. Maruyama H, Tamauchi H, lizuka M and Nakano T: The role of NK cells in antitumor activity of dietary fucoidan from Undaria pinnatifida sporophylls (Mekabu). Planta Med 72: 1415-1417, 2006.

7. Hu Y, Cheng SC, Chan KT, Ke Y, Xue B, Sin FW, Zeng C and Xie Y: Fucoidin enhances dendritic cell-mediated T-cell cytotoxicity against NY-ESO-1 expressing human cancer cells. Biochem Biophys Res Commun 392: 329-334, 2010.

8. Fujiwara D, Inoue S, Wakabayashi $\mathrm{H}$ and Fujii T: The antiallergic effects of lactic acid bacteria are strain dependent and mediated by effects on both Th1/Th2 cytokine expression and balance. Int Arch Allergy Immunol 135: 205-215, 2004.

9. Nonaka Y, Izumo T, Izumi F, Maekawa T, Shibata H, Nakano A, Kishi A, Akatani K and Kiso Y: Antiallergic effects of Lactobacillus pentosus strain S-PT84 mediated by modulation of Th1/Th2 immunobalance and induction of IL-10 production. Int Arch Allergy Immunol 145: 249-257, 2008.

10. Masuda S, Yamaguchi H, Kurokawa T, Shirakami T, Tsuji RF and Nishimura I: Immunomodulatory effect of halophilic lactic acid bacterium Tetragenococcus halophilus Th221 from soy sauce moromi grown in high-salt medium. Int J Food Microbiol 121: 245-252, 2008.

11. Nagao F, Nakayama M, Muto T and Okumura K: Effects of a fermented milk drink containing Lactobacillus casei strain Shirota on the immune system in healthy human subjects. Biosci Biotechnol Biochem 64: 2706-2708, 2000. 
12. Ishida $Y$, Nakamura F, Kanzato H, Sawada D, Hirata H, Nishimura A, Kajimoto O and Fujiwara S: Clinical effects of Lactobacillus acidophilus strain L-92 on perennial allergic rhinitis: a double-blind, placebo-controlled study. J Dairy Sci 88: 527-533, 2005.

13. Nishimura I, Igarashi T, Enomoto T, Dake Y, Okuno Y and Obata A: Clinical efficacy of halophilic lactic acid bacterium Tetragenococcus halophilus Th221 from soy sauce moromi for perennial allergic rhinitis. Allergol Int 58: 179-185, 2009.

14. Shu Q and Gill HS: Immune protection mediated by the probiotic Lactobacillus rhamnosus HN001 (DR20) against Escherichia coli O157:H7 infection in mice. FEMS Immunol Med Microbiol 34: 59-64, 2002

15. Corr SC, Gahan CG and Hill C: Impact of selected Lactobacillus and Bifidobacterium species on Listeria monocytogenes infection and the mucosal immune response. FEMS Immunol Med Microbiol 50: 380-388, 2007

16. Yasui H, Kiyoshima J and Hori T: Reduction of influenza virus titer and protection against influenza virus infection in infant mice fed Lactobacillus casei Shirota. Clin Diagn Lab Immunol 11: 675-679, 2004

17. Maeda N, Nakamura R, Hirose Y, Murosaki S, Yamamoto Y, Kase $\mathrm{T}$ and Yoshikai Y: Oral administration of heat-killed Lactobacillus plantarum L-137 enhances protection against influenza virus infection by stimulation of type I interferon production in mice. Int Immunopharmacol 9: 1122-1125, 2009.

18. Kawase M, He F, Kubota A, Harata G and Hiramatsu M: Oral administration of lactobacilli from human intestinal tract protects mice against influenza virus infection. Lett Appl Microbiol 51: 6-10, 2010

19. Kobayashi N, Saito T, Uematsu T, Kishi K, Toba M, Kohda N and Suzuki T: Oral administration of heat-killed Lactobacillus pentosus strain b240 augments protection against influenza virus infection in mice. Int Immunopharmacol 11: 199-203, 2011.

20. Romagnani S: Regulation of the T cell response. Clin Exp Allergy 36: 1357-1366, 2006.

21. Romagnani S: The role of lymphocytes in allergic disease. J Allergy Clin Immunol 105: 399-408, 2000.

22. Morita H, He F, Fuse T, Ouwehand AC, Hashimoto H, Hosoda M, Mizumachi K and Kurisaki J: Cytokine production by the murine macrophage cell line J774.1 after exposure to lactobacilli. Biosci Biotechnol Biochem 66: 1963-1966, 2002.

23. Cross ML, Ganner A, Teilab D and Fray LM: Patterns of cytokine induction by gram-positive and gram-negative probiotic bacteria FEMS Immunol Med Microbiol 42: 173-180, 2004.

24. Lee JB, Hayashi K, Hashimoto M, Nakano T and Hayashi T: Novel antiviral fucoidan from sporophyll of Undaria pinnatifida (Mekabu). Chem Pharm Bull (Tokyo) 52: 1091-1094, 2004.

25. Maruyama H, Tanaka M, Hashimoto M, Inoue M and Sasahara T: The suppressive effect of Mekabu fucoidan on an attachment of Cryptosporidium parvum oocysts to the intestinal epithelial cells in neonatal mice. Life Sci 80: 775-781, 2007.

26. Tsuji RF, Hoshino K, Noro Y, Tsuji NM, Kurokawa T, Masuda T, Akira S and Nowak B: Suppression of allergic reaction by lambda-carrageenan: Toll-like receptor 4/MyD88-dependent and -independent modulation of immunity. Clin Exp Allergy 33 249-258, 2003

27. Trinchieri G: Proinflammatory and immunoregulatory functions of interleukin-12. Int Rev Immunol 16: 365-396, 1998.
28. Nie X, Shi B, Ding Y and Tao W: Preparation of a chemically sulfated polysaccharide derived from Grifola frondosa and its potential biological activities. Int J Biol Macromol 39: 228-233, 2006.

29. Vetvicka V, Vetvickova J, Frank J and Yvin JC: Enhancing effects of new biological response modifier beta-1,3 glucan sulfate PS3 on immune reactions. Biomed Pharmacother 62: 283-288, 2008.

30. Cho ML, Lee BY and You SG: Relationship between oversulfation and conformation of low and high molecular weight fucoidans and evaluation of their in vitro anticancer activity. Molecules 16: 291-297, 2010.

31. Adhikari U, Mateu CG, Chattopadhyay K, Pujol CA, Damonte EB and Ray B: Structure and antiviral activity of sulfated fucans from Stoechospermum marginatum. Phytochemistry 67: 2474-2482, 2006.

32. Yang C, Chung D, Shin IS, Lee H, Kim J, Lee Y and You S: Effects of molecular weight and hydrolysis conditions on anticancer activity of fucoidans from sporophyll of Undaria pinnatifida. Int J Biol Macromol 43: 433-437, 2008.

33. Fearon DT and Locksley RM: The instructive role of innate immunity in the acquired immune response. Science 272: 50-53, 1996.

34. Akira S, Takeda K and Kaisho T: Toll-like receptors: critical proteins linking innate and acquired immunity. Nat Immunol 2: 675-680, 2001.

35. Koizumi S, Wakita D, Sato T, Mitamura R, Izumo T, Shibata H, Kiso Y, Chamoto K, Togashi Y, Kitamura H and Nishimura T: Essential role of Toll-like receptors for dendritic cell and NK1.1 ${ }^{+}$ cell-dependent activation of type 1 immunity by Lactobacillus pentosus strain S-PT84. Immunol Lett 120: 14-19, 2008

36. Hisbergues M, Magi M, Rigaux P, Steuve J, Garcia L, Goudercourt D, Pot B, Pestel J and Jacquet A: In vivo and in vitro immunomodulation of Der $\mathrm{p} 1$ allergen-specific response by Lactobacillus plantarum bacteria. Clin Exp Allergy 37: 1286-1295, 2007.

37. Rigaux P, Daniel C, Hisbergues M, Muraille E, Hols P, Pot B, Pestel $\mathbf{J}$ and Jacquet $\mathrm{A}$ : Immunomodulatory properties of Lactobacillus plantarum and its use as a recombinant vaccine against mite allergy. Allergy 64: 406-414, 2009.

38. Shimosato T, Kitazawa H, Katoh S, Tohno M, Iliev ID, Nagasawa C, Kimura T, Kawai Y and Saito T: Augmentation of Th-1 type response by immunoactive AT oligonucleotide from lactic acid bacteria via Toll-like receptor 9 signaling. Biochem Biophys Res Commun 326: 782-787, 2005.

39. Lin YL, Shieh CC and Wang JY: The functional insufficiency of human $C D 4^{+} C D 25^{\text {high }}$ T-regulatory cells in allergic asthma is subjected to TNF- $\alpha$ modulation. Allergy 63: 67-74, 2008

40. Smith M, Tourigny MR, Noakes P, Thornton CA, Tulic MK and Prescott SL: Children with egg allergy have evidence of reduced neonatal $\mathrm{CD} 4{ }^{+} \mathrm{CD} 25^{+} \mathrm{CD} 127^{\mathrm{lo} /}$ regulatory $\mathrm{T}$ cell function. J Allergy Clin Immunol 121: 1460-1466, 2008.

41. Enomoto M, Noguchi S, Hattori M, Sugiyama H, Suzuki Y, Hanaoka A, Okada S and Yoshida T: Oral administration of Lactobacillus plantarum NRIC0380 suppresses IgE production and induces $\mathrm{CD} 4{ }^{+} \mathrm{CD} 25^{+} \mathrm{Foxp} 3^{+}$cells in vivo. Biosci Biotechnol Biochem 73: 457-460, 2009. 